Д. М. Гребнева https://orcid.org/0000-0002-7511-9327

Е. C. Васева https://orcid.org/0000-0001-5442-3170

Н. В. Бужинская https://orcid.org/0000-0001-5821-136X

\title{
Формирование компетенции самоорганизации в процессе подготовки будущего специалиста ИТ-сферы
}

Для цитирования: Гребнева Д. М., Васева Е. С., Бужинская Н. В. Формирование компетенции самоорганизации в процессе подготовки будущего специалиста ИТ-сферы // Ярославский педагогический вестник. 2020. № 5 (116). C. 75-81. DOI 10.20323/1813-145X-2020-5-116-75-81

В настоящее время существует тенденция увеличения заинтересованности работодателей в трудоустройстве специалистов, способных к работе в удаленном режиме. Возможность организовать работу сотрудников в удаленном режиме имеет для работодателя ряд преимуществ: экономия расходов, связанных с содержанием рабочего места, обеспечение кадрами удаленных или труднодоступных территорий (филиалов). Российское законодательство также направлено на урегулирование трудовых взаимоотношений в этой сфере. Обозначенные факторы определяют актуальность целенаправленной подготовки будущего специалиста ИТ-сферы к удаленной работе.

Цель данного исследования - определить содержательные и организационные условия процесса подготовки будущего специалиста ИТ-сферы к удаленной работе.

В статье выделены этапы удаленной работы, которые могут быть реализованы в процессе обучения будущего специалиста ИТ-сферы: выбор набора средств взаимодействия, согласование цели работы и выбор форм представления промежуточных результатов по этапам решения задачи, планирование работы, выбор средств решения, решение задачи, представление результатов, самооценивание. Делается вывод о том, что готовность к удаленной работе определяется наличием умений личности в области самоорганизации. Показаны составляющие компетенции самоорганизации применительно к специалистам ИТ-сферы в аспекте обозначенных этапов организации удаленной работы. Для всех составляющих представлены показатели сформированности. Предложенная структура деятельности была применена при обучении курсу «Вебтехнологии» студентов, обучающихся по направлению 09.03.03 «Прикладная информатика». Моделирование ситуации будущей профессиональной деятельности реализовывалось в условиях дистанционного обучения в период пандемии коронавируса, что позволило создать наиболее реалистичные условия удаленной работы. Полученные результаты показали, что представленную систему организации образовательного процесса и оценивания способности к выполнению работы удаленно можно успешно использовать при выполнении студентами профессионально-ориентированных задач.

Ключевые слова: удаленная работа, профессионально-ориентированная задача, модель профессиональной деятельности, самоорганизация, будущий специалист ИТ-сферы, веб-технологии.

\section{M. Grebneva, E. S. Vaseva, N. V. Buzhinskaya}

\section{Formation of the competence of self-organization in the process of training the future IT specialist}

Currently, there is a tendency of increasing employers' interest in employing specialists capable of working remotely. The ability to organize the work of employees remotely has a number of advantages for the employer: saving costs associated with maintaining the workplace, providing staff to remote or hard-to-reach areas (branches). Russian legislation is also aimed at regulating labor relations in this area. These factors determine the relevance of the targeted training of a future IT specialist for remote work.

The purpose of this study is to determine the content and organizational conditions for the process of preparing a future IT specialist for remote work.

The article highlights the stages of remote work that can be implemented in the process of training a future IT specialist: choosing a set of interaction tools, agreeing on the goal of work and choosing forms for presenting intermediate results by stages of solving a problem, planning work, choosing a solution, solving a problem, present results, self-assessment. It is concluded that the willingness to work remotely is determined by the presence of

(C) Гребнева Д. М., Васева Е. С., Бужинская Н. В., 2020 
personality skills in the field of self-organization. The components of the competence of self-organization are shown as applied to IT specialists in the aspect of the indicated stages of organizing remote work. Formation indicators are proposed for all components. The proposed structure of activities was applied in teaching the course «Web technologies» to students enrolled in the direction 09.03.03 «Applied Informatics». Simulation of the situation of future professional activity was implemented in the context of distance learning during the coronavirus pandemic, which made it possible to create the most realistic conditions for remote work. The obtained results showed that the presented system of organizing the educational process and assessing the ability to perform work remotely can be successfully used when students perform professionally oriented tasks.

Keywords: remote work, professionally oriented task, model of professional activity, self-organization, future IT specialist, web technologies.

Введение. В современным условиях в высшем образовании актуальным становится поиск новых форм обучения, целью которых является не только усвоение студентами компетенций, предусмотренных стандартами подготовки, но и приобретение опыта деятельности. В условиях конкуренции на рынке труда выпускник должен уметь быстро и эффективно решать задачи профессиональной деятельности, объективно оценивать полученный результат и вносить необходимые коррективы. Кроме того, будущий специалист должен уметь организовать свою работу в удаленном режиме. Особенно этот аспект актуален для специалистов ИТ-сферы, для которых характерны хорошие знания в области различных видов информационнокоммуникационных технологий. Кроме того, выполнение ряда проектов в ИТ-сфере осуществляется с привлечением нескольких специалистов, которые могут быть разделены территориально. Следовательно, возникает задача дистанционного взаимодействия участников данного проекта.

Цель исследования - определить содержательные и организационные условия процесса подготовки будущего специалиста ИТ-сферы к удаленной работе.

Методология исследования. В Трудовом кодексе Российской Федерации вводится понятие «дистанционная работа». Под дистанционной (удаленной) работой понимается выполнение определенной трудовым договором трудовой функции вне места нахождения работодателя, его филиала, представительства, иного обособленного структурного подразделения (включая расположенные в другой местности), вне стационарного рабочего места, территории или объекта, прямо или косвенно находящихся под контролем работодателя, при условии использования для выполнения данной трудовой функции и для осуществления взаимодействия между работодателем и работником по вопросам, связанным с ее выполнением, информационно-телекоммуникационных сетей общего пользования, в том числе интернета [Трудовой кодекс ..., 2020]. В проекте Федерального закона «О внесении изменений в Трудовой кодекс Российской Федерации в части регулирования дистанционной и удаленной работы» от 16 июня 2020 г. регламентируются особенности заключения и изменения условий трудового договора о дистанционной (удаленной) работе, требования к дистанционным работникам, размер оплаты труда работников и др. [Проект федерального ..., 2020]. Если специалист не имеет постоянного работодателя, то он считается фрилансером. Фрилансера отличает более гибкий график работы, наличие возможности самостоятельно выбирать проекты, в которых он будем принимать участие, при отсутствии постоянного места работы. Различия между удаленной работой и фрилансом более подробно рассмотрены в исследовании Ф. Д. Конобевцева, Н. И. Лаас, Е. В. Гуровой, И. А. Романовой [Конобевцев, 2019]. При этом, независимо от способа организации работы специалиста (под руководством работодателя или «на себя»), удаленный режим имеет как свои достоинства, так и недостатки. Вместе с тем, несмотря на недостатки, удаленный способ организации работы становится все более распространенной практикой во многих странах [Малышев, 2018; Матвеева, 2019; Нагибина, 2019; Стребков, 2016; Eurofound. New ..., 2015].

К достоинствам удаленной работы для работодателя можно отнести

- экономию расходов, связанных с содержанием рабочего места [Howe, 2009];

- обеспечение кадрами удаленных или труднодоступных территорий (филиалов) [Handal, $2018]$.

Работник также имеет ряд преимуществ при организации своей трудовой деятельности в удаленной форме:

- возможность выполнения трудовых операций лицами с ограниченными физическими возможностями;

- возможность самостоятельно планировать график своей работы;

- возможность трудоустройства в организации, территориально удаленные от места проживания [Reading, 2019]; 
- мобильность;

- низкий уровень эмоционального выгорания за счет возможности организации работы в собственном темпе, отсутствия конфликтов;

- возможность контролировать уровень своих доходов и расходов;

- возможность параллельно решать задачи, не связанные с основным местом работы.

Основным недостатком удаленной работы является необходимость работника в постоянной самоорганизации трудовой деятельности. Часть работников, в отсутствие руководства, испытывают затруднения не только с планированием графика своей работы, но и с отбором задач, которые они могут эффективно и своевременно решить в данный момент. Эффективность удаленной работы зависит от того, насколько специалист ориентируется на собственные внутренние принципы и может ли самостоятельно создать условия для ее оптимизации [Sungurova, 2017]. Таким образом, именно наличие умений личности в области самоорганизации определяет готовность к удаленной работе.

Проблеме самоорганизации деятельности, в том числе и самоорганизации студентов, посвящены исследования В. И. Андреева, Е. Ю. Мандриковой, С. А. Богомаз, А. И. Ивашенко, В. В. Гура и др.

В. И. Андреев утверждает, что самоорганизация проявляется в планировании своих дел не только на ближайший период, но и на будущее [Андреев, 2015]. Самоорганизация деятельности это способность личности рационально распределять свое время на решение поставленных задач [Мандрикова, 2010]. Самоорганизация предполагает процесс упорядоченной сознательной деятельности личности, направленный на достижение поставленных целей [Гура, 2016; Носкова, 2009]. Самоорганизованный человек более автономен с учетом самостоятельного управления своими делами.

С. И. Коковихина отмечает, что самоорганизация - это сознательная работа обучаемого над собой в целях совершенствования познавательных, практических, эмоциональных, нравственных и волевых способностей и черт характера, а не только средство достижения частных целей обучения [Каковихина, 2010].

В исследованиях [Богомаз, 2011; Мандрикова, 2010] склонность личности к самоорганизации можно оценить на основе приведенных ниже шкал:

- шкала «целеустремленность»- умение поставить цель и выбрать средства для ее достижения;
- шкала «планомерность» - умение составить план деятельности;

- шкала «настойчивость» - умение действовать согласно поставленному плану, вовремя исправлять ошибки и преодолевать затруднения;

- шкала «фиксация» - умение оценивать результаты своей работы в целом и на промежуточных этапах;

- шкала «ориентация на настоящее» - умение акцентировать внимание на наиболее важных в данный момент задачах;

- шкала «самоорганизация»- умение принять помощь извне.

Таким образом, обучение самоорганизации в высшем образовании предполагает формирование у студента комплекса умений и навыков, направленных на сознательное управление течением своей жизни с учетом внутренних резервов и индивидуальных способностей. Если рассматривать самоорганизацию как некую «внутреннюю технологию» [Филиогло, 2013], то ее освоение возможно в процессе вовлечения студентов в активную деятельность по решению профессиональноориентированных задач.

Результаты и их обсуждение. В Федеральном государственном образовательном стандарте закреплены требования к выпускнику, обучающемуся по направлению 09.03.03 «Прикладная информатика (по отраслям)», одно из которых сформированность общекультурной компетенции «способность к самоорганизации и самообразованию» [Приказ Минобрнауки ..., 2017]. Способность к самоорганизации является ключевым фактором эффективной удаленной работы. Как правило, современный студент еще в период обучения определяет для себя предрасположенность к той или иной форме деятельности [Орлов, 2014]. Кроме того, на сегодняшний день многие компании заинтересованы в трудоустройстве специалистов, способных работать удаленно. Все обозначенные факторы определяют актуальность целенаправленной подготовки будущего специалиста ИТ-сферы к удаленной работе. В процессе подготовки к удаленной работе важно включать в содержание обучения профессиональноориентированные задачи, создавать условия, моделирующие будущую профессиональную деятельность. Применимо к специалистам ИТ-сферы компетенция «Способность к самоорганизации и самообразованию» в аспекте этапов организации удаленной работы может иметь составляющие, которые показаны в Таблице 1 . Также в таблице отражены показатели, по которым педагог может отследить, является ли составляющая компетенции сформированной. 
Таблица 1

Показатели сформированности компетенцуии самоорганизацуии в аспекте этапов удаленной работы

\begin{tabular}{|c|c|c|}
\hline Этап удаленной работы & $\begin{array}{l}\text { Составляющая компетен- } \\
\text { ции «Способность к само- } \\
\text { организации и самообразо- } \\
\text { ванию» }\end{array}$ & Показатель сформированности \\
\hline $\begin{array}{l}\text { Согласование цели работы и } \\
\text { выбор форм представления } \\
\text { промежуточных результатов } \\
\text { по этапам проекта }\end{array}$ & $\begin{array}{l}\text { Способность ставить цель } \\
\text { проекта }\end{array}$ & $\begin{array}{l}\text { Цель решения профессионально-ориентированной задачи } \\
\text { согласована с собственными целями. Цель представлена в } \\
\text { виде иерархической структуры. Определены способы и фор- } \\
\text { мы промежуточных результатов, необходимых для ее дости- } \\
\text { жения. Четкое представление вида ожидаемого результата } \\
\text { (документ, схема, сайт, расчет) }\end{array}$ \\
\hline $\begin{array}{l}\text { Выбор набора средств взаи- } \\
\text { модействия }\end{array}$ & $\begin{array}{l}\text { Способность оптимального } \\
\text { выбора цифровых инстру- } \\
\text { ментов взаимодействия }\end{array}$ & $\begin{array}{l}\text { Определены и обоснованы критерии выбора средств взаимо- } \\
\text { действия. Согласно критериям выбраны оптимальные сред- } \\
\text { ства удаленного взаимодействия в процессе решения профес- } \\
\text { сионально-ориентированных задач. В набор средств входят } \\
\text { виртуальная доска, система видеоконференций, файловый } \\
\text { сервер и т. д. }\end{array}$ \\
\hline Планирование работы & $\begin{array}{l}\text { Способность планирования } \\
\text { деятельности }\end{array}$ & $\begin{array}{l}\text { Составлен детализированный план работы по проекту, опре- } \\
\text { делены первостепенные и второстепенные задачи, сроки. } \\
\text { Анализ плана позволяет сделать вывод, что цель решения } \\
\text { задачи будет достигнута. В плане отражены точки предостав- } \\
\text { ления промежуточных результатов }\end{array}$ \\
\hline $\begin{array}{l}\text { Выбор средств решения } \\
\text { задач }\end{array}$ & $\begin{array}{l}\text { Способность выбора } \\
\text { средств решения задачи }\end{array}$ & $\begin{array}{l}\text { Выбраны оптимальные средства разработки с точки зрения } \\
\text { затрачиваемых ресурсов, требований заказчика, возможно- } \\
\text { стей разработчика, уменьшения рисков проекта }\end{array}$ \\
\hline Решение задачи & $\begin{array}{l}\text { Способность планомерного } \\
\text { решения задачи }\end{array}$ & $\begin{array}{l}\text { В установленные сроки предоставляет результаты отдельных } \\
\text { этапов решения задачи. Результаты решения отдельных эта- } \\
\text { пов задачи соответствуют требованиям }\end{array}$ \\
\hline Самооценивание & Способность самооценки & $\begin{array}{l}\text { Выполняет самооценку своей деятельности согласно выде- } \\
\text { ленным преподавателем критериям, предлагает собственные } \\
\text { критерии, выделяет недочеты в собственной работе, предла- } \\
\text { гает способы исправления ошибок, сокращения сроков реше- } \\
\text { ния задачи }\end{array}$ \\
\hline
\end{tabular}

Предложенная система была реализована при оценивании результатов обучения студентов заочного отделения по курсу «Веб-технологии». Моделирование ситуации будущей профессиональной деятельности реализовывалось в условиях дистанционного обучения в период пандемии коронавируса. Студентам была предложена следующая профессионально-ориентированная задача:

Для агентства по развитию туризма нужно сверстать макет главной странищы веб-сайта для виртуального тура по городу Нижний Тагил. Дизайн страницы должен эффективно поддерживать иель сайта - увеличение посетителей виртуальных экскурсий города. Вы должны выбирать ивета, шрифты, графические элементьл, исходя из сферы деятельности организачии (корпоративный стиль ассоииируется с желтокрасной цветовой гаммой). В качестве промежуточных итогов необходимо предоставить дерево целей проекта, график работь, прототип вебстраницы, макет страниць в формате *.jpg. Итоговым результатом должен стать шаблон страницы с использованием html5 и css3.

Перед началом непосредственной работы над макетом веб-страницы, студенты должны были самостоятельно составить дерево целей и определиться со временем и средствами исполнения каждого этапа задания в рамках окончательного срока сдачи проекта (Таблица 2).

После определения целей и средств проекта студенты приступают к созданию прототипа, дизайна и шаблона веб-страницы с помощью выбранных программных средств, руководствуясь составленным графиком работы.

Кроме того, студент самостоятельно оценивает каждый промежуточный этап работы и сравнивает свою оценку с оценкой преподавателя (Таблица 3 ). 
Таблица 2

График выполнения задания

\begin{tabular}{|l|l|l|}
\hline Этап работь & $\begin{array}{l}\text { Цифровой инструмент взаимо- } \\
\text { действия / средство решения } \\
\text { задачи }\end{array}$ & Время исполнения \\
\hline 1. Разработка прототипа главной страницы & & \\
\hline $\begin{array}{l}\text { 2. Утверждение прототипа главной страницы пре- } \\
\text { подавателем }\end{array}$ & & \\
\hline $\begin{array}{l}\text { 3. Разработка дизайна главной страницы в графи- } \\
\text { ческом редакторе }\end{array}$ & & \\
\hline $\begin{array}{l}\text { 4. Самооценка дизайна страницы по заданным кри- } \\
\text { териям }\end{array}$ & & \\
\hline $\begin{array}{l}\text { 5. Утверждение дизайна главной страницы препо- } \\
\text { давателем }\end{array}$ & & \\
\hline 6. Верстка шаблона & & \\
\hline $\begin{array}{l}\text { 7. Оценка шаблона студентом по заданным крите- } \\
\text { риям }\end{array}$ & & \\
\hline 8. Итоговая оценка проекта преподавателем & & \\
\hline
\end{tabular}

Таблица 3

Базовые критерии оиенки качества шаблона веб-страницы

\begin{tabular}{|c|c|c|}
\hline \multirow{2}{*}{\multicolumn{3}{|c|}{$\begin{array}{l}\text { Критерий } \\
\text { Прототип страницы }\end{array}$}} \\
\hline & & \\
\hline \multicolumn{3}{|l|}{$\begin{array}{l}\text { Наличие основных структурных элементов веб- } \\
\text { страницы (логотип, заголовок, меню, содержимое, } \\
\text { подвал) }\end{array}$} \\
\hline \multicolumn{3}{|l|}{ Наличие интерактивных элементов } \\
\hline \multicolumn{3}{|l|}{ Удобство расположения элементов веб-страницы } \\
\hline \multicolumn{3}{|l|}{ Дизайн страницы } \\
\hline \multicolumn{3}{|l|}{$\begin{array}{l}\text { Соответствие корпоративному стилю и цветовой } \\
\text { гамме }\end{array}$} \\
\hline \multicolumn{3}{|l|}{ Читабельность текста } \\
\hline \multicolumn{3}{|l|}{ Удобство поиска информации } \\
\hline \multicolumn{3}{|l|}{ Понятность использования графических символов } \\
\hline \multicolumn{3}{|l|}{ Сочетание цветов веб-страницы } \\
\hline \multicolumn{3}{|l|}{ Сочетание шрифтов веб-страницы } \\
\hline \multicolumn{3}{|l|}{ Шаблон страницы } \\
\hline \multicolumn{3}{|l|}{$\begin{array}{l}\text { Успешное прохождение проверки на валидность } \\
\text { http://validator.w3.org }\end{array}$} \\
\hline \multicolumn{3}{|l|}{ Код css представлен в одном стилевом файле } \\
\hline \multicolumn{3}{|l|}{$\begin{array}{l}\text { Верстка идентично отображается в последних вер- } \\
\text { сиях браузеров Chrome, Opera, Firefox, Safari, Edge, } \\
\text { а также в Internet Explorer 11+ }\end{array}$} \\
\hline \multicolumn{3}{|l|}{$\begin{array}{l}\text { Веб-страница нормально смотрится на минималь- } \\
\text { ной для макета ширине, верстка проходит тест на } \\
\text { переполнение контентом }\end{array}$} \\
\hline \multicolumn{3}{|l|}{$\begin{array}{l}\text { В корне проекта имеются папки css, img, js или } \\
\text { аналогичные. Главная страница имеет название } \\
\text { index.html. В названиях и расширениях файлов нет } \\
\text { заглавных букв и пробелов, использованы только } \\
\text { латинские символы }\end{array}$} \\
\hline \multicolumn{3}{|l|}{$\begin{array}{l}\text { Единообразное написание и форматирование кода } \\
\text { в HTML, CSS }\end{array}$} \\
\hline Выбран подходящий формат изображений & & \\
\hline
\end{tabular}

В итоговой оценке преподаватель отмечает как качество выполнения всех этапов разработки вебстраницы (прототип, дизайн, шаблон), так и качество компетенции самоорганизации студентов по ее составляющим: способности оптимального выбора цифровых инструментов взаимодействия, способности ставить цель проекта, планировать деятельность, выбрать средства решения задачи, планомерно решить задачу, способности осуществлять самооценку. В результате студент получает отметку за созданную веб-страницу (оценивание по пятибалльной шкале) и оценку проявленной самоорганизации по шести критериям (оценивание каждого критерия по трехбалльной 
шкале, где 0 - способность не проявлена, 1 - способность проявлена не в полной мере, 2 - способность проявлена) с рекомендациями преподавателя по улучшению работы. При этом результаты оценивания каждого критерия могут отличаться, например, студент может получить 2 балла за выбор средств решения задачи, выбор цифровых инструментов взаимодействия, 1 балл - за план своей работы. Подобная система оценивания позволяет отслеживать затруднения каждого студента и вносить необходимые изменения в процесс подготовки.

Оценивание не только конечного результата выполнения проекта, но и процесса работы над его созданием (постановка цели, составление графика, соблюдение временных рамок и т. д.) позволяет развивать самоорганизацию студентов. Будущие ИТ-специалисты постепенно учатся эффективно планировать график своей работы, отбирать задачи, которые они могут успешно и своевременно решить в данный момент.

Заключение. Полученные результаты показали, что представленную систему организации образовательного процесса и оценивания способности к выполнению работы удаленно можно успешно использовать при выполнении студентами профессионально-ориентированных задач. При освоеннии курса «Веб-технологии» ситуация сложилась таким образом, что условия решения профессионально-ориентированной задачи были наиболее реалистичными, так как студенты выполняли всю работу удаленно в связи с пандемией.

\section{Библиографический список}

1. Андреев В. И. Педагогическая эвристика для творческого саморазвития многомерного мышления и мудрости : монография. Казань : Центр инновационных технологий, 2015. 288 с.

2. Богомаз С. А. Типологические особенности самоорганизации деятельности // Вестник Томского государственного университета. 2011. № 344. С. 163-166.

3. Гура В. В. Роль самоорганизации учебной деятельности студентов в развитии профессионально значимых компетенций / В.В.Гура, И.Ю.Луцева // Международный журнал экспериментального образования. 2016. № 11-3. С. 149-152.

4. Каковихина С. И. Самостоятельная работа и самоорганизация как дидактические средства развития общекультурных компетенций : учебно-методическое пособие / С.И.Каковихина, Г.В.Чиконина. Томск : Изд-во Томского политехнического университета, 2010. 202 c.

5. Конобевцев Ф. Д. Удаленная работа: технологии и опыт организации / Ф. Д. Конобевцев, Н.И.Лаас, Е. В. Гурова, И. А. Романова // Вестник университета. 2019. № 7. С. 9-17.
6. Малышев А. А. Эволюция практики удаленной работы в России и за рубежом // Вестник Сибирского института бизнеса и информационных технологий. 2018. № 3 (27). С. 33-40.

7. Мандрикова Е. Ю. Разработка опросника самоорганизации // Психологическая диагностика. 2010. № 2. C. 87-111.

8. Матвеева Н. С. Перспективы развития фриланса в условиях современной России / Н. С. Матвеева, М. А. Черкасова // Вестник университета. 2019.№ 7. C. $18-25$.

9. Нагибина Н. И. Удаленная работа: эволюция, анализ, перспективы / Н. И. Нагибина, О. Р. Имамутдинова, А. А. Дятлова // Управление персоналом и интеллектуальными ресурсами в России. 2019. Т. 8. № 4. С. 50-59.

10. Носкова Т. Н. Формирование компетенции самоорганизации студентов как основы обучения в современной образовательной среде университета / Т. Н. Носкова, С. С. Куликова // Известия Российского государственного педагогического университета им. А. И. Герцена. 2009. Вып. 83. С. 78-88.

11. Орлов В. Б. Удаленная работа как новая реалия трудовых отношений: анализ факторов предрасположенности к удаленной работе / В.Б. Орлов, Е. И. Бураншина // Вестник Югорского государственного университета. 2014. № 4. С. 40-46.

12. Приказ Минобрнауки России от 19.09.2017 № 922 «Об утверждении федерального государственного образовательного стандарта высшего образования - бакалавриат по направлению подготовки 09.03.03 Прикладная информатика». URL: http://www.consultant.ru/document/cons_doc_LAW_280 602/a2a0576b12371b0a799f132a2dbbf2 $\overline{\mathrm{fe}} 411 \overline{\mathrm{e}} 860 \mathrm{a}-$ (Дата обращения: 20.08.2020).

13. Проект Федерального закона «О внесении изменений в Трудовой кодекс Российской Федерации в части регулирования дистанционной и удаленной работы». URL: https://rg.ru/2020/06/16/proekt-udalenkasite-dok.html (Дата обращения: 20.08.2020).

14. Стребков О. Д. Самостоятельная занятость на рынке удаленной работы: распространение инновационной трудовой практики / Д. О. Стребков, А. В. Шевчук, М. О. Спирина // Мониторинг общественного мнения: Экономические и социальные перемены. 2016. № 6. С. 89-106.

15. «Трудовой кодекс Российской Федерации» от 30.12.2001 № 197-Ф3 (ред. от 31.07.2020) (с изм. и доп., вступ. в силу с 13.08.2020). URL: http://www.consultant.ru/document/cons_doc_LAW_346 83/adca37e8038a44ab5499c589bf6205dce6af12d6/ (Дата обращения: 20.08.2020).

16. Филиогло Л. Д. Основы самоорганизации : учебно-методическое пособие / Л. Д. Филиогло, В. В. Нюренберг. Тольятти : Изд-во ТГУ, 2013. 234 с.

17. Eurofound. New forms of employment. Luxembourg : Publications Office of the European Union. 2015. $168 \mathrm{p}$.

URL: https://www.eurofound.europa.eu/sites/default/files/ef_pu blication/field_ef_document/ef1461en.pdf. 
18. Handal B. Choosing to Teach in Rural and Remote Schools: The Zone of Free Movement / B. Handal, K. Watson, P. Petocz, M. Maher // Education Research and Perspectives. 2018. Vol. 45. P. 1-32.

19. Howe G. Demystifying Remote Access // School Business Affairs. 2009. Vol. 75. № 4. P. 8.

20. Reading C. Educating for Sustainability in Remote Locations / C. Reading, C. Khupe, M. Redford, D. Wallin, T. Versland, N. Taylor, P. Hampton // Rural Educator. 2019. Vol. 40. № 2. P. 43-53.

21. Sungurova N. L. Self-organization features of students with different strategies of network communication / N. L. Sungurova, A. V. Ivashchenko, N. B. Karabushchenko // Psychology. Historical-critical Reviews and Current Researches. 2017. 6 (4A). P. 160-171.

\section{Reference list}

1. Artamonova V. V. Razvitie koncepcii gejmifikacii v XXI veke $=$ Development of the concept of gamification in the XXI century // ISOM. 2018. № 2-2. S. 37-43.

2. Babaeva A. V. Osobennosti gejmifikacii pri rabote $\mathrm{s}$ trudovymi resursami: filosofskij aspekt $=$ Features of gamification during the work with human resources: philosophical aspect / A. V. Babaeva, A. A. Kljuev // Vestnik Mininskogo universiteta. 2017. № 4 (21). URL: https://cyberleninka.ru/article/n/osobennostigeymifikatsii-pri-rabote-s-trudovymi-resursamifilosofskiy-aspekt (Data obrashhenija: 01.08.2020).

3. Bajborodova L. V. Pedagogicheskie tehnologii dlja sovremennogo pokolenija $=$ Pedagogical technologies for the modern generation/ L. V. Bajborodova, N. V. Tamarskaja // Jaroslavskij pedagogicheskij vestnik. 2020. № 3. S. 8-16.

4. Bredihina N. S. Fenomen gejmifikacii v prodvizhenii distancionnyh obrazovatel'nyh uslug $=$ The phenomenon of gamification in the promotion of distance educational services // Kommunikativnye issledovanija. 2017. № 2 (12). S. 96-108.

5. Varenina L. P. Gejmifikacija v obrazovanii = Gamification in education // ISOM. 2014. № 6-2. S. 314-317.

6. Vepreva T. B. Leksika v obuchenii inostrannym jazykam = Vocabulary in foreign language education // Vestnik Severnogo (Arkticheskogo) federal'nogo universiteta. Serija: Gumanitarnye i social'nye nauki. 2010. № 6. S. 104-107.

7. Govorov A. I. Ocenka aktual'nosti razrabotki metodov ispol'zovanija sredstv gejmifikacii i igrovyh tehnologij v sistemah upravlenija obucheniem $=$ Assess of the relevance of developing methods for using gamification tools and gaming technologies in training management systems / A. I. Govorov, M. M. Govorova, Ju. O. Valitova // Komp'juternye instrumenty v obrazovanii. 2018. № 2. S. 39-54.

8. Zimina D. V. Osobennosti realizacii strukturnoj gejmifikacii na platforme WordPress dlja sozdanija distancionnyh obuchajushhih kursov $=$ Features of implementation of structural gamification on the WordPress platform for creation of distance training courses / D. V. Zimina, O. O. Kozak, V. I. Pogorelov, D. A. Shuklin // Vestnik evrazijskoj nauki. 2016. № 3
(34). URL: https://cyberleninka.ru/article/n/osobennostirealizatsii-strukturnoy-geymifikatsii-na-platforme-

wordpress-dlya-sozdaniya-distantsionnyh-obuchayuschihkursov (Data obrashhenija: 01.08.2020).

9. Karavaev N. L. Analiz programmnyh servisov i platform, obladajushhih potencialom dlja gejmifikacii obuchenija = Analysis of software services and platforms with potential for learning gamification / N. L. Karavaev, E. V. Soboleva // Koncept. 2017. № 8. URL: https://cyberleninka.ru/article/n/analiz-programmnyhservisov-i-platform-obladayuschih-potentsialom-dlyageymifikatsii-obucheniya (Data obrashhenija: 01.08.2020).

10. Mironova A. A. Gejmifikacija v obuchenii russkomu jazyku kak inostrannomu = Gamification in teaching Russian as a foreign language // Meteor-Siti. 2017. № 2. S. 44-47.

11. Orlova O. V. Gejmifikacija kak sposob organizacii obuchenija $=$ Gamification as a way to organize learning / O. V. Orlova, V. N. Titova // Vestnik TGPU. 2015. № 9 (162). S. 60-64.

12. Pogorelov V. I. Sravnitel'nyj analiz metodov strukturnoj i soderzhatel'noj gejmifikacii dlja sozdanija jelektronnogo uchebnogo kursa. Start-2015= Comparative analysis of structural and meaningful gamification methods for creating an electronic training course. Start2015 : materialy Obshherossijskoj molodezhnoj nauch.tehn. konf. / V. I. Pogorelov, D. V. Zimina, O. O. Kozak. Sankt-Peterburg : Balt. gos. tehn. un-t, 2015. 64 s.

13. Polesjuk R.S. Ob jeffektivnosti ispol'zovanija igry pri obuchenii inostrannomu jazyku $=$ About the effectiveness of using the game in teaching a foreign language // Vestnik KemGU. 2012. № 4. (52). T. 4. S. 275-278.

14. Titova S. V. Teoretiko-metodicheskie osnovy ispol'zovanija jelektronnyh obrazovatel'nyh resursov $\mathrm{V}$ obuchenii inostrannyh jazykov $=$ Theoretical and methodological foundations of using electronic educational resources in teaching foreign languages / S. V. Titova, K. V. Aleksandrova // Vestnik Moskovskogo universiteta. Serija 19: Lingvistika i mezhkul'turnaja kommunikacija. 2018. № 3. S. 113-123.

15. Titova S. V. Gejmifikacija v obuchenii inostrannym jazykam: psihologo-didakticheskij i metodicheskij potencial $=$ Gamification in foreign languages training: psychological-didactic and methodical potential / S. V. Titova, K. V. Chirkizova // Pedagogika i psihologija obrazovanija. 2019. № 1. S. 135-152.

16. Bellotti F., Berta R., De Gloria A., Primavera L. Enhancing the educational value of video games. Computers in Entertainment, 2009. V. 7, no. 2, pp. 1-18.

17. Kapp K. M., Blair L., Blair R. The Gamification of Learning and Instruction Fieldbook: Ideas into Practice. John Wiley \& Sons, 2013. 480 p.

18. Scott A. D. WordPress for Education. Birmingham: Packt Publishing Ltd, 2012. 144 p.

19. The Model for Introduction of Gamification into E-learning in Higher Education / M. Urh, G. Vukovic, E. Jereb, R. Pintar// Procedia - Social and Behavioral Sciences. 2015. V. 197. P. 388-397. 